\title{
Aerosolised prostacyclin for pulmonary hypertension in neonates
}

\author{
L Bindl, H Fahnenstich, U Peukert
}

\begin{abstract}
Aerosolised prostacyclin (PGI $)$ was administered to two neonates with pulmonary hypertension to dilate the pulmonary vessels selectively. The alveolararterial oxygen gradient fell from $\mathbf{7 3 . 2}$ (patient 1) and $71.8 \mathrm{kPa}$ (patient 2) to 33.8 and $26.7 \mathrm{kPa}$ respectively. Systemic blood pressure remained stable while pulmonary blood pressure declined in patient 1. When inhaled, $\mathbf{P G I}$ seems to improve oxygenation, mainly due to reduction of intrapulmonary shunting.

(Arch Dis Child 1994; 71: F214-F216)
\end{abstract}

The intravenous use of vasodilatory drugs in the treatment of pulmonary hypertension is limited by an attendant drop in systemic vascular resistance. Furthermore, intrapulmonary shunting may be enhanced. Interest has therefore been focused on the inhalation of nitric oxide. It induces selective pulmonary vasodilation in persistent pulmonary hypertension of the neonate ${ }^{1}$ and in pulmonary hypertensive crisis after repair of cardiac malformations. ${ }^{2}$

It has been shown that the inhalation of prostacyclin $\left(\mathrm{PGI}_{2}\right)$ reverses the pulmonary vasoconstriction in hypoxic dogs to a similar degree to nitric oxide. ${ }^{3}$ Recently its effective use in patients with adult respiratory distress syndrome has been reported. ${ }^{4}$ We describe the effect of nebulised $\mathrm{PGI}_{2}$ in two neonates with pulmonary hypertension.

\section{Methods}

Pulmonary hypertension was diagnosed by continuous wave Doppler. Systolic pulmonary blood pressure was calculated as the sum of central venous pressure and the gradient between right ventricle and right atrium measured by continuous wave Doppler. Tricuspid regurgitation was present in both patients; there was no pulmonary stenosis. Systemic blood pressure was measured via an umbilical arterial line in patient 1 and an arterial line in the left radial artery in patient 2 .

Alveolar-arterial oxygen difference $\left(\mathrm{AaDO}_{2}\right)$ was calculated by the simplified formula:

Centre for Paediatrics, University of Bonn, D-53113 Bonn,

Adenauerallee 119,

Germany

L Bindl

H Fahnenstich

U Peukert

Correspondence to:

Dr Bindl.

Accepted 31 March 1994
In both patients a time cycled, pressure limited, continuous flow infant ventilator was (where $\mathrm{FIO}_{2}=$ fractional inspired oxygen, $\mathrm{PaCO}_{2}=$ arterial carbon dioxide tension, used. After parental consent was obtained, aerosolised $\mathrm{PGI}_{2}$ was applied over a period of 45 minutes. Ventilator settings were constant and the transcutaneous measurements of oxygen tension and carbon dioxide tension remained stable for one hour before administration of $\mathrm{PGI}_{2}$. We used a SPAG-2nebuliser, generating an aerosol with a mean particle diameter of $1.3 \mu \mathrm{m}$. The nebuliser was driven by an air oxygen mixture with an $\mathrm{FIO}_{2}$ equal to the ventilator gas at a pressure of 179 $\mathrm{kPa}$. The ventilator gas flow $(8 \mathrm{1} / \mathrm{min})$ was reduced according to the amount of nebuliser flow (5 $1 / \mathrm{min}) . \mathrm{FIO}_{2}$, peak inspiratory pressure, and mean arterial pressure remained unchanged. The $\mathrm{PGI}_{2}$ solution in glycine buffer contained $2.5 \mathrm{mg} \mathrm{PGI} / \mathrm{ml}$ and was delivered at a rate of $6 \mathrm{ml} / \mathrm{hour}$ to the ventilator circuit next to the tracheal tube connector. The dose of aerosolised $\mathrm{PGI}_{2}$ that passed the endotracheal tube was calculated as follows:

$\mathrm{PGI}_{2}(\mathrm{ng} / \mathrm{kg} / \mathrm{min})=250 \mathrm{~T}_{\mathrm{i}} \times /\left(\mathrm{T}_{\mathrm{i}}+\mathrm{T}_{\mathrm{e}}\right) /$ body weight $(\mathrm{kg})$

$\left(\mathrm{T}_{\mathrm{i}}=\right.$ the inspiratory and $\mathrm{T}_{\mathrm{e}}=$ the expiratory time).

$\mathrm{FIO}_{2}$ was reduced when the oxygen saturation exceeded $95 \%$.

\section{Case reports}

CASE 1

A boy, weighing $4080 \mathrm{~g}$ (large for gestational age), was born at 35 weeks' gestation and delivered spontaneously to an obese nondiabetic 31 year old mother (gravida 2, para 2). His Apgar scores were 6 and 9 at one and five minutes respectively. The amniotic fluid was clear. There were no clinical or laboratory signs of infection. At 6 hours of age, nasal continuous positive airway pressure with an $\mathrm{FIO}_{2}$ of 0.3 was initiated owing to increasing respiratory distress (respiratory rate 80 breaths $/ \mathrm{min}, \mathrm{PaO}_{2} 4.67 \mathrm{kPa}, \mathrm{PaCO}_{2} 7.86 \mathrm{kPa}$, $\mathrm{pH} 7 \cdot 20$ ). At 20 hours of age, mechanical ventilation had to be established because of increased oxygen demand. A chest radiograph was normal except for slight generalised opacification. Pulmonary hypertension was diagnosed. Atrial shunting, predominantly right to left, was detected by colour Doppler. At 48 hours of age the $\mathrm{AaDo}_{2}$ was $73.2 \mathrm{kPa}$, $\mathrm{PaCO}_{2} 6 \cdot 00 \mathrm{kPa}$, and $\mathrm{pH} 7 \cdot 37$. The patient was ventilated at a rate of 60 breaths/min with a flow of $8 \mathrm{1} / \mathrm{min}$, an inspiratory to expiratory ratio of $1: 2$ and an inspiratory pressure of 28/3 $\mathrm{cm} \mathrm{H}_{2} \mathrm{O}$ at onset. The dose of aerosolised $\mathrm{PGI}_{2}$ was $20 \mathrm{ng} / \mathrm{kg} / \mathrm{min}$. Oxygenation improved (figure); there was a slight decrease in pulmonary arterial pressure (table); atrial 


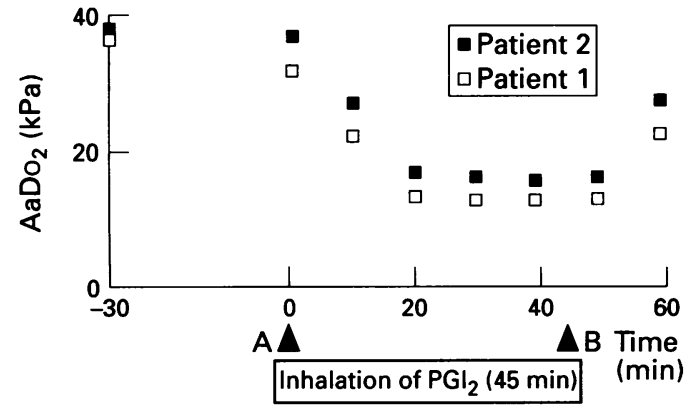

Changes in $\mathrm{AaDO}_{2}$ during inhalation (start A, end B) of $\mathrm{PGI}_{2}$.

shunting was exclusively left to right. Because of the beneficial effect aerosolised $\mathrm{PGI}_{2}$ was continued for eight hours. The patient was extubated 40 hours after onset of the therapeutic trial. Echocardiographic findings had normalised.

\section{CASE 2}

A boy with hydrops, weighing $360 \mathrm{~g}$, was born at 37 weeks' gestation and delivered spontaneously to a 28 year old mother (gravida 3, para 2). Apgar scores were 7 and 8 at one and five minutes respectively. Right sided hydrothorax had been diagnosed at 23 weeks' gestation and fetal thoracocentesis was performed six times. Ascites had developed in the 34th gestational week.

The child was intubated 12 minutes after birth because of hypoxaemia and retractions. $\mathrm{He}$ was paralysed with vecuronium. Despite drainage of the pleural effusion, the right lung expanded poorly. At 11 hours of age dopamine $(5 \mu \mathrm{g} / \mathrm{kg} / \mathrm{min})$ was infused because of persistent oliguria. Because of metabolic acidosis with an arterial $\mathrm{pH}$ of $7 \cdot 22$ and suspected pulmonary hypertension, a continuous infusion of sodium bicarbonate was started. At 24 hours of age continuous wave Doppler revealed suprasystemic pulmonary pressure (table). By means of colour Doppler examination we detected predominantly right to left atrial and ductal shunting. The $\mathrm{AaDO}_{2}$ was $71.8 \mathrm{kPa}, \mathrm{PaCO}_{2} 6.40 \mathrm{kPa}$, and $\mathrm{pH} 7.39$. The ventilator was set at a rate of 70 breaths $/ \mathrm{min}$ with a flow of $8 \mathrm{1} / \mathrm{min}$, an inspiratory to expiratory ratio of $1: 1.4$ and an inspiratory pressure of $27 / 3 \mathrm{~cm} \mathrm{H}_{2} \mathrm{O}$ at onset. The calculated dose of aerosolised $\mathrm{PGI}_{2}$ was $28 \mathrm{ng} / \mathrm{kg} / \mathrm{min}$. Oxygenation improved instantaneously (figure), but without any major

Arterial pH, systemic systolic and diastolic blood pressure and systolic pulmonary arterial pressure 30 minutes before, 30 minutes after start, and 15 minutes after the end of $P G I_{2}$ inhalation

\begin{tabular}{|c|c|c|c|}
\hline & \multicolumn{3}{|c|}{ Time (min) } \\
\hline & -30 & +30 & +60 \\
\hline \multicolumn{4}{|l|}{ pH } \\
\hline Case 1 & $7 \cdot 42$ & $7 \cdot 36$ & $7 \cdot 37$ \\
\hline Case 2 & $7 \cdot 38$ & $7 \cdot 35$ & $7 \cdot 33$ \\
\hline \multicolumn{4}{|c|}{ Systolic/diastolic pressure $(\mathrm{mm} \mathrm{Hg})$} \\
\hline $\begin{array}{l}\text { Case } 1 \\
\text { Case } 2\end{array}$ & $\begin{array}{l}62 / 69 \\
53 / 31\end{array}$ & $\begin{array}{l}63 / 32 \\
66 / 39\end{array}$ & $\begin{array}{l}57 / 33 \\
68 / 35\end{array}$ \\
\hline \multicolumn{4}{|c|}{ Pulmonary arterial pressure $(\mathrm{mm} \mathrm{Hg})$} \\
\hline Case 1 & 47 & 37 & - \\
\hline Case 2 & 86 & 81 & - \\
\hline
\end{tabular}

effect on pulmonary arterial pressure. Thirty minutes after the end of the inhalative administration of $\mathrm{PGI}_{2}$ the drug was infused intravenously at a rate of $11 \mathrm{ng} / \mathrm{kg} / \mathrm{min}$ over 24 hours with only slight effect on oxygen saturation. Pulmonary arterial pressure hypertension had disappeared, the chest radiograph showed a better expansion of the right lung. The child was extubated after 16 days on the ventilator.

\section{Discussion}

Treatment of pulmonary hypertension in the neonate aims to reduce pulmonary vascular resistance while maintaining systemic resistance. Alkalinisation is the mainstay of treatment. Intravenous administration of vasodilatory drugs is accompanied by a concomitant fall in systemic vascular resistance, which may also entail persistent right to left shunting and arterial hypotension. Furthermore, in patients with impaired alveolar ventilation, a reversal in hypoxic pulmonary vasoconstriction may increase perfusion of poorly ventilated regions, leading to arterial desaturation. The reports on the first clinical experiences using nitric oxide in patients of all age groups demonstrated that local pulmonary vasodilation can be achieved by inhalation of a short lived vasodilator drug. In adults with respiratory distress syndrome, inhaled nitric oxide not only improved pulmonary hypertension but also decreased intrapulmonary shunting, whereas the infusion of $\mathrm{PGI}_{2}$ led to arterial desaturation. ${ }^{5}$

Inhalation of $\mathrm{PGI}_{2}$ at a rate of 0.87 $\mathrm{ng} / \mathrm{kg} / \mathrm{min}$ in dogs reversed hypoxic pulmonary vasoconstriction. ${ }^{3}$ A solution of $0.43 \mu \mathrm{g}$ $\mathrm{PGI}_{2} / \mathrm{ml}$ was aerosolised by a jet nebuliser to particles with a diameter of $<2 \mu \mathrm{m}$. The use of nebulised $\mathrm{PGI}_{2}$ in man was first reported by Hardy et al who administered up to 1000 $\mathrm{ng} / \mathrm{kg} / \mathrm{min}$ in asthma patients. ${ }^{6}$ The use of $\mathrm{PGI}_{2}$ aerosol with a mean particle diameter of $2.7 \mu \mathrm{m}$ in three patients with adult respiratory distress syndrome produced a clinically relevant reduction in intrapulmonary shunting. The calculated dose was $17-50 \mathrm{ng} / \mathrm{kg} / \mathrm{min}$. A $20 \%$ reduction in pulmonary arterial pressure without a significant reduction in systemic blood pressure was achieved. In our patients $\mathrm{AaDO}_{2}$ decreased dramatically; pulmonary arterial pressure fell slightly in patient 1 and was not substantially reduced in patient 2 . In patient 2 the persistence of pulmonary hypertension, which had also not been reduced by intravenous $\mathrm{PGI}_{2}$, may have been due to the poor expansion of the right lung. The dose of nebulised $\mathrm{PGI}_{2}$ was in the same range as in the study of Walmrath and colleagues. ${ }^{4}$ When it reached the alveolar region, however, the dose was effectively smaller as there is a proportionally larger dead space in newborn infants.

We did not observe any drop in systemic blood pressure. The improved oxygenation can be explained mainly by a reduction of ventilation perfusion mismatching, because only a slight reduction of the pulmonaryto-systemic pressure ratio occurred in patient 1 and suprasystemic pressure persisted in 
patient 2. Bronchodilation as the underlying mechanism is unlikely in the two cases.

$\mathrm{PGI}_{2}$, when intravenously infused, has a short half life of 2-3 minutes. After clinical use for more than 10 years, no toxic side effects have been reported. Therefore the risk of inhalative administration appears to be low. Devices for drug inhalation in ventilated patients are commonly available.

Nitric oxide seems to be becoming the drug of choice for pulmonary hypertension in ventilated patients. Nevertheless its use is not free of hazards: a fatal case after accidental overdose has been described. Furthermore, its use requires special equipment for monitoring.

Because of the lack of any known toxicity for $\mathrm{PGI}_{2}$ and its uncomplicated mode of inhalative application it may be a useful alternative. Further controlled trials of aerosolised $\mathrm{PGI}_{2}$ are warranted in neonates with pulmonary hypertension, especially when intrapulmonary shunting contributes to hypoxaemia.

1 Roberts JD, Polaner DM, Lang P, Zapol WM. Inhaled nitric oxide in persistent pulmonary hypertension of the newborn. Lancet 1992; 340: 818-9.

2 Wessel DL, Adatia I. Thompson J, Kulik TJ. Inhaled nitric oxide and acetylcholine in the evaluation of pulmonary hypertension and endothelial function after cardiohypertension and endothelial function after cardiopulmonary bypass. Circulation 1993; 88 (part 1): 2128-38.
3 Welte M, Zwissler B, Habazettl H, Messmer K. PGI 2 aeroso versus nitric oxide for selective pulmonary vasodilation in hypoxic pulmonary vasoconstriction. Eur Surg Res 1993 25: $329-40$.

4 Walmrath D, Schneider T, Pilch J, Grimminger F, Seegar W. Aerosolized prostacyclin in adult respiratory distress syndrome. Lancet 1993; 342: 961-2.

5 Rossaint R, Falke KJ, López F, Slama K, Pison U, Zapol WM. Inhaled nitric oxide for the adult respiratory distress WM. Inhaled nitric oxide for the adult respiratc

6 Hardy CC, Bradding P, Robinson C, Holgate ST Bronchoconstrictor and anti-bronchoconstrictor properties of inhaled prostacyclin in asthma. $\mathcal{F}$ Appl Physiol 1988; 64 1567-74.

\title{
Hydrops fetalis caused by a blood group antibody usually undetected in routine screening
}

\author{
J Smoleniec, N Anderson, G Poole
}

\begin{abstract}
A case of isoimmunisation in pregnancy caused by antibodies to the $K \mathrm{p}^{\mathrm{a}}$ red blood cell antigen is described. The preceding pregnancy had resulted in fetal hydrops for which no cause was found as the antibody screening cells used to investigate the fetal hydrops were $K^{a}{ }^{a}$ negative. This case emphasises the importance of serological screening at a reference laboratory for low frequency red cell antigens before a diagnosis of non-immune hydrops is made.
\end{abstract}

(Arch Dis Child 1994; 71: F216-F217)

The Penny $\left(K \mathbf{p}^{\mathrm{a}}\right)$ and Rautenberg $\left(\mathrm{Kp}^{\mathrm{b}}\right)$ antigens are part of the Kell blood group system. The incidence of $\mathrm{Kp}^{\mathrm{a}}$ is $2 \%$ in the white population. ${ }^{1}$ Anti-Kp ${ }^{\mathrm{a}}$ is known to cause haemolytic disease of the newborn but is not usually associated with hydrops fetalis or haemolysis severe enough to require intrauterine transfusion. $^{2}$

Bristol

J Smoleniec

Regional Transfusion Centre, Bristol

$N$ Anderson

G Poole

Correspondence to Mr J Smoleniec,

St Michael's Hospital,

St Michael's Hill,

Bristol

BS2 8EG.

Accepted 23 May 1994
Her first preonancy seven years previo resulted in a normal vaginal delivery. Five years later she had a spontaneous abortion at
7 weeks' gestation. In the third pregnancy, intrauterine death of the fetus occurred at 17 weeks' gestation. The fetus was hydropic but no fetal cells were obtained for red cell grouping or antibody identification. No irregular antibodies were found in the maternal serum, and no other cause for the hydrops was identified. She had no history of previous blood transfusion.

Her red cells were phenotyped as group A $\mathrm{Rh} \mathrm{D}$ positive, $\mathrm{Kp}(\mathrm{a}-\mathrm{b}+)$. Her husband's red cells were phenotyped as group $\mathrm{O} R \mathrm{Rh} D$ positive, $\mathrm{Kp}(\mathrm{a}+\mathrm{b}+)$; being heterozygous for the $\mathrm{Kp}^{\mathrm{a}}$ antigen, and therefore giving the baby a $50 \%$ chance of being $\mathrm{Kp}^{\mathrm{a}}$ positive. The titre of anti-Kp $\mathrm{K}^{\mathrm{a}}$ was 256 at 17 weeks' gestation, and conservative management was advised with weekly ultrasound scanning for fetal hydrops and maternal blood sampling every two weeks. At 24 weeks' gestation the titre of anti- $\mathrm{Kp}^{\mathrm{a}}$ had risen to 1000 and at 25 weeks, early fetal ascites was noted by ultrasound scanning. Intrauterine fetal blood sampling revealed a severely anaemic fetus with a haemoglobin concentration of $40 \mathrm{~g} / \mathrm{l}$. The direct Coombs test (direct antiglobulin test) was positive and the fetal cells were typed as group $O \mathrm{Rh} D$ positive, $\mathrm{Kp}(\mathrm{a}+\mathrm{b}+)$. Spectrophotometric measurement of the deviation in optical density of the amniotic fluid at $450 \mathrm{~nm}(\Delta 450)$ was unhelpful in predicting the severity of the fetal anaemia.

The pregnancy was managed with regular intrauterine transfusions up to 32 weeks' 